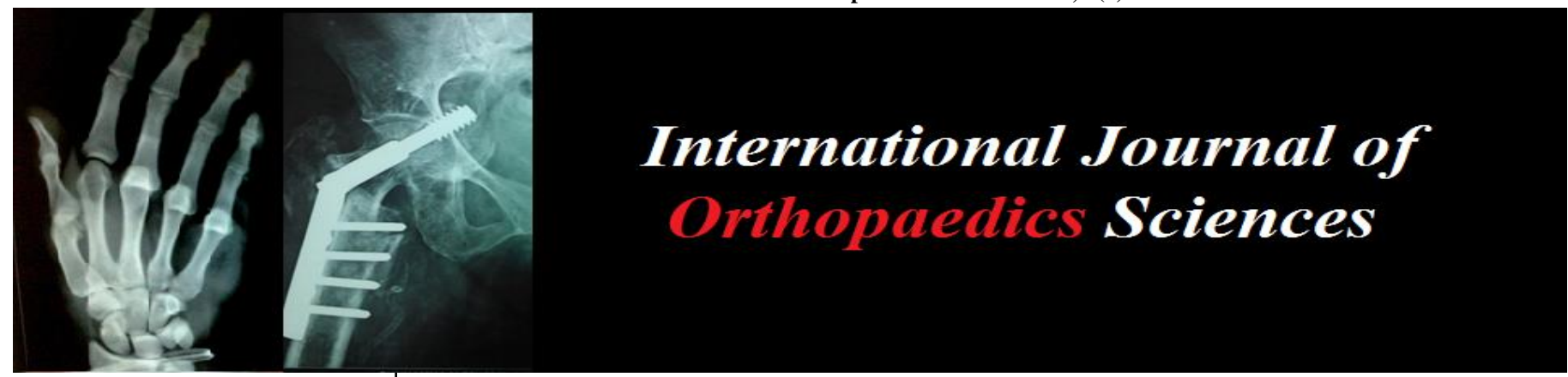

E-ISSN: 2395-1958

P-ISSN: 2706-6630

IJOS 2020; 6(2): 35-38

(C) 2020 IJOS

www.orthopaper.com

Received: 23-02-2020

Accepted: 24-03-2020

Dr. Nikhil Gangane

Senior Resident, Sanjay Gandhi

Memorial Hospital, New Delhi, India

Dr. Ullas Mahesh

Assistant Professor,

Sri Siddhartha Medical College,

T Begur, Bangalore, Karnataka,

India

Dr. Babu B Putti

JNMC, KLE, Belgaum,

Karnataka, India
Corresponding Author:

Dr. Ullas Mahesh

Assistant Professor,

Sri Siddhartha Medical College,

T Begur, Bangalore, Karnataka,

India

\section{A hospital based prospective study to assess the functional outcome of nailing versus plating in fracture shaft of humerus}

\author{
Dr. Nikhil Gangane, Dr. Ullas Mahesh and Dr. Babu B Putti
}

DOI: https://doi.org/10.22271/ortho.2020.v6.i2a.2015

\section{Abstract}

Introduction: The treatment of humeral shaft fractures using intramedullary nailing (IMN) and dynamic compression plating (DCP) is controversial. The present study was designed to evaluate the functional outcome, fracture union time and complications of IMN and DCP for fractures of humerus shaft.

Methods: This hospital based one year prospective study was done in the Department of Orthopaedics, KLES Dr. Prabhakar Kore Hospital and Medical Research Centre, Belgaum from January 2014 to December 2014. A total of 30 patients with humeral shaft fractures were studied. Based on the method of treatment, patients were divided into two groups of 15 each as group A (Nailing) and group (Plating). Patients were followed up for the fracture union, complications and functional outcome based on Constant Murley score.

Results: Majority of the patients (80\%) in group A were males while in group B, 53.33\% of the patients were males. $(p=0.121)$. The mean age was comparable in both the groups $(34.33 \pm 11.27$ vs. $33.20 \pm 11.73$ years; $\mathrm{p}=0.789$ ). There was almost equal distribution of patients in group $\mathrm{A}$ and $\mathrm{B}$ with respect to fracture side, type, mode of injury and associated injuries $(p>0.050)$. In group A, shoulder stiffness and superficial infection were present in $13.33 \%$ and $6.67 \%$ of the patients while in group B, radial nerve palsy and superficial infection were noted in $6.67 \%$ and $13.33 \%$ of the patients respectively.

Conclusion and Interpretation: Intramedullary nailing and DCP are equally effective for the treatment of shaft of humerus fractures.

Keywords: Dynamic compression plating, fracture shaft humerus, intramedullary nailing

\section{Introduction}

Fractures of the humeral shaft are commonly encountered in orthopedic clinics, and these fractures make up 1.31 to $3 \%$ of all fractures. Large epidemiologic studies report a bimodal distribution with a minor peak in the third decade consisting mainly of men sustaining highenergy trauma and a second major peak in the eighth decade, mostly women with osteoporotic fractures resulting from simple falls.

Fractures are often classified by their location: proximal third, midshaft and distal third. The widely used and accepted AO classification scheme classifies fractures by type and severity. Type A fractures are simple spiral, oblique and transverse fractures. Spiral, bending and fragmented wedge fractures are classified as B1, 2 and 3 and Type $\mathrm{C}$ fractures are complex fractures.

The mechanism of injury may be direct or indirect. In the case of indirect force the accident involves falling onto the elbow or hand. Direct force is applied during impact of the folded arm with an edge or, more often, during direct impact of the abducted arm with an obstacle. Depending on the mechanism, the fracture may include a bending wedge. High energy trauma often produces multifragmentary and/or severely dislocated fractures. The severity of these injuries can be classified with reference to the Injury Severity Score (ISS).

The clinical evaluation of a patient with a humeral shaft fracture should comprise complete physical examination and a detailed neurovascular examination. Conventional radiographs in two planes are the standard diagnostic procedure.

The treatment approaches for these injuries continue to evolve as advances are made in both non-operative and operative management. The humeral shaft is covered with muscles and is well-vascularized. A slight malunion is functionally tolerated. 
It is generally agreed that the majority of humeral shaft fractures are best treated non-operatively, but there are indications for primary or secondary operative treatment in some situations. Non-operative or conservative treatment may involve the use of casts or functional braces. In cases associated with severe complications, an operative intervention is preferred.

\section{Objectives}

The objective of this study was to determine the best functional outcome for shaft of humerus fractures, nailing or plating.

\section{Methodology}

The present study was conducted in the Department of Orthopaedics, during the period from January 2014 to December 2014.

\section{Study design}

The study design was a hospital based one year prospective study.

\section{Duration and period of study}

Present one year study was conducted from January 2014 to December 2014.

\section{Place}

This study was done in the Department of Orthopaedics.

\section{Source of Data}

Patients presenting with mid-shaft humerus fractures undergoing surgery (nailing/plating) in the Department of Orthopaedics, were included in the study.

\section{Sample Size}

A total of 30 patients undergoing humerus nailing or plating and fulfilling the selection criteria during the study period were enrolled.

\section{Sample size calculation}

Based on the universal sampling method, sample size was calculated by considering the $80 \%$ of average hospital statistics on mid-shaft humerus fractures over a period of three years with minimum effect size of 30 patients.

\section{Selection Criteria}

\section{Inclusion Criteria}

- Humeral shaft fractures treated within 1 week by nailing and plating.

- $\quad$ Age: $>18$ years.

\section{Exclusion Criteria}

- Patients who had fractures with epiphyseal plate open.

- Fracture line extending into the metaphysic.

- Patients who were lost for follow up.

- Pathologic fractures.
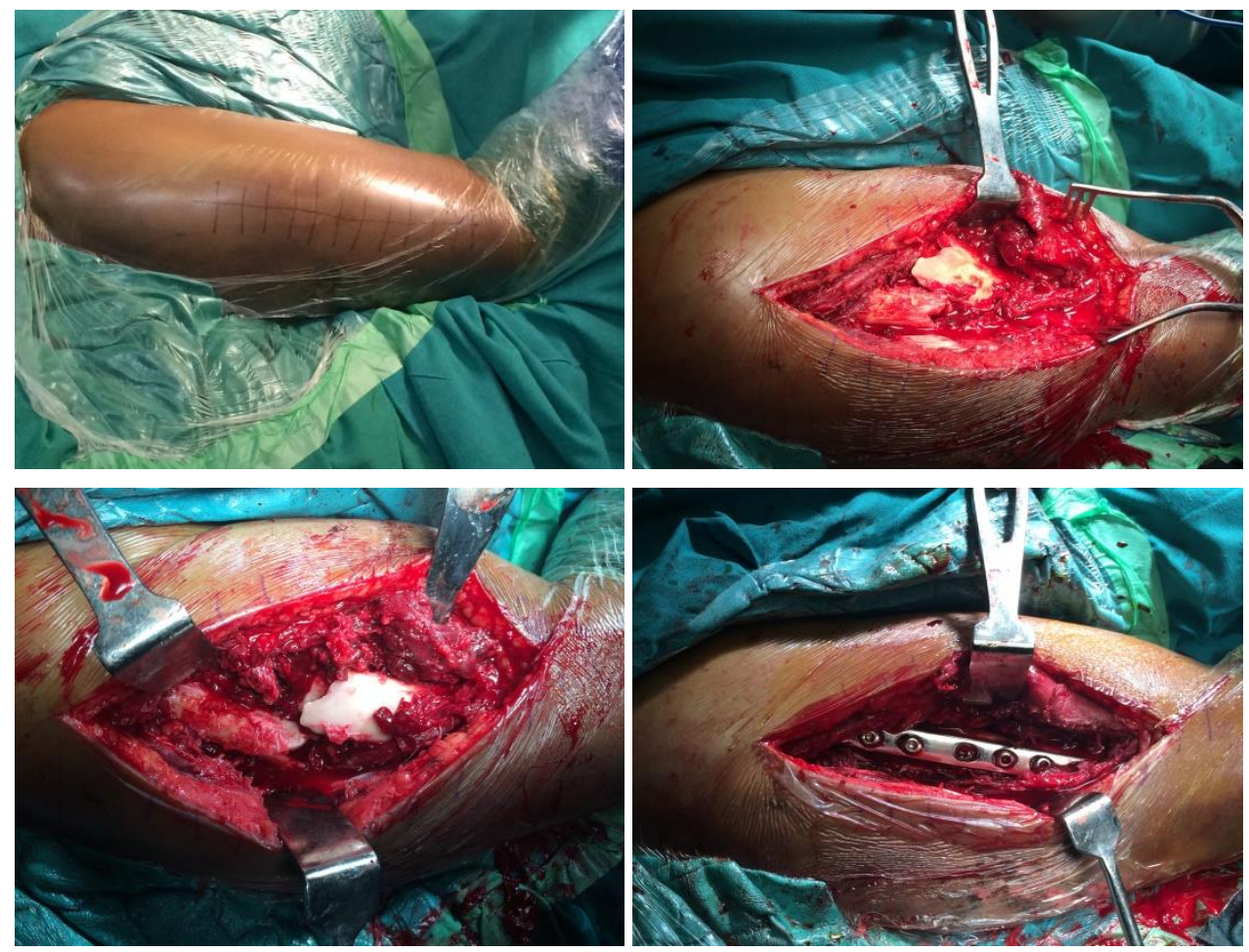

Intraoperative Pics

\section{Results}

The present hospital based one year prospective study was conducted in the Department of Orthopaedics, KLES Dr. Prabhakar Kore Hospital and Medical Research Centre, Belgaum. A total of 30 patients with humeral shaft fractures underwent either nailing or plating. The patients were divided into two groups of 15 each as group A (Nailing) and group (Plating).

The data obtained was analysed and the final results and observations were tabulated as below.

Table 1: Sex distribution

\begin{tabular}{|c|c|c|c|c|}
\hline \multirow{2}{*}{ Sex } & \multicolumn{2}{|c|}{ Group A (n=15) } & \multicolumn{2}{c|}{ Group B (n=15) } \\
\cline { 2 - 5 } & Number & Percentage & Number & Percentage \\
\hline Male & 12 & 80.00 & 8 & 53.33 \\
\hline Female & 3 & 20.00 & 7 & 46.67 \\
\hline Total & 15 & 100.00 & 15 & 100.00 \\
\hline
\end{tabular}




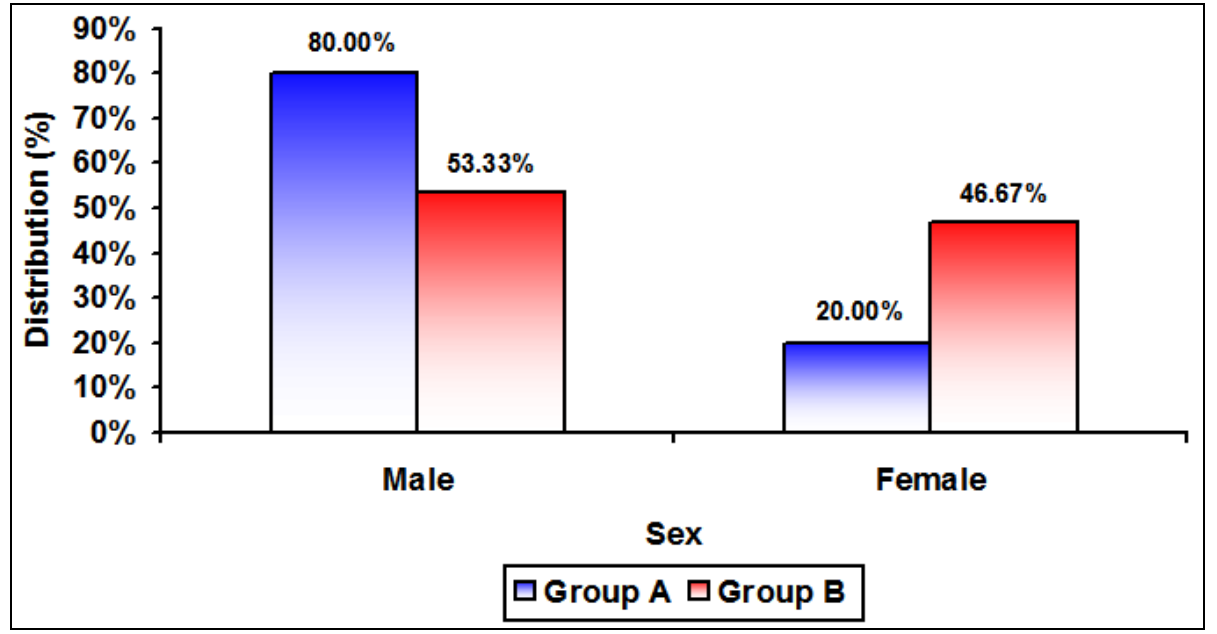

Graph 1: Sex distribution

In the present study $80 \%$ of the patients in group A were males compared to $53.33 \%$ in group $\mathrm{B}$. The male to female ratio in group $\mathrm{A}$ was $4: 1$ and in group $\mathrm{B}$, it was $1.14: 1$.
However, this difference was statistically not significant $(\mathrm{p}=0.121)$.

Table 2: Age distribution

\begin{tabular}{|c|c|c|c|c|}
\hline \multirow{2}{*}{ Age group (Years) } & \multicolumn{2}{|c|}{ Group A (n=15) } & \multicolumn{2}{c|}{ Group B (n=15) } \\
\cline { 2 - 5 } & Number & Percentage & Number & Percentage \\
\hline$\leq 30$ & 6 & 40.00 & 6 & 40.00 \\
\hline 31 to 45 & 7 & 46.67 & 7 & 46.67 \\
\hline 46 to 60 & 2 & 13.33 & 2 & 13.33 \\
\hline Total & 15 & 100.00 & 15 & 100.00 \\
\hline
\end{tabular}

$$
\mathrm{p}=1.000
$$

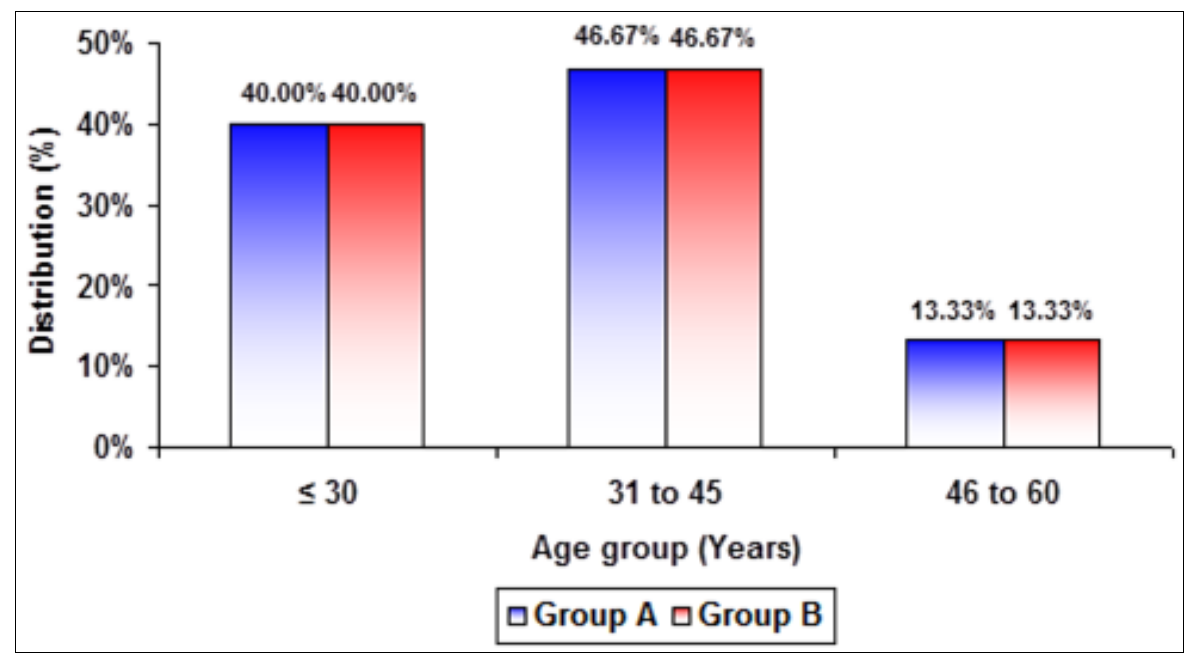

Graph 2: Age distribution

In this study $46.67 \%$ of the patients each in group A and group B were aged between 31 to 45 years $(p=1.000)$.

Table 3: Side

\begin{tabular}{|c|c|c|c|c|}
\hline \multirow{2}{*}{ Side } & \multicolumn{2}{|c|}{ Group A (n=15) } & \multicolumn{2}{|c|}{ Group B (n=15) } \\
\hline & Number & Percentage & Number & Percentage \\
\hline Left & 5 & 33.33 & 9 & 60.00 \\
\hline Right & 10 & 66.67 & 6 & 40.00 \\
\hline Total & 15 & 100.00 & 15 & 100.00 \\
\hline
\end{tabular}




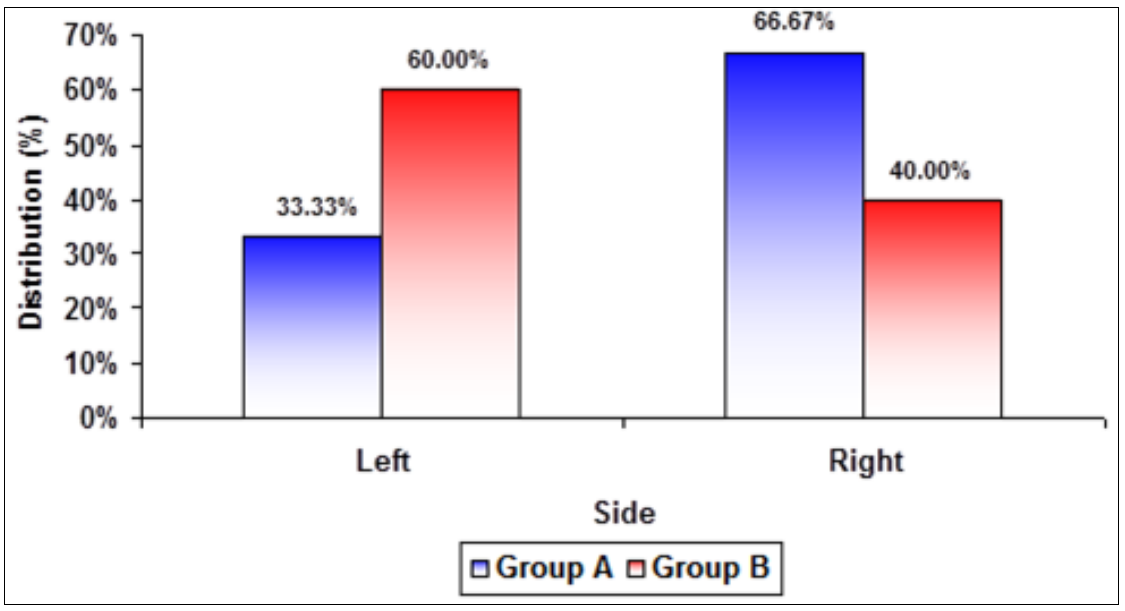

Graph 3: Side

In the present study $66.67 \%$ of the patients in group $\mathrm{A}$ sustained fracture on right side compared to $60 \%$ of the patients in group B on left side. However this difference was statistically not significant $(\mathrm{p}=0.143)$.

\section{Discussion}

The operative treatment of acute humeral shaft fractures is still fraught with a high complication rate, even with current fracture fixation techniques. The optimal method of humeral shaft fracture fixation remains in debate.

Two techniques under investigation include intramedullary nailing and plate fixation. Plating provides satisfactory results but requires extensive dissection, and meticulous redial nerve protection. The plate may fail in osteoporotic bone. With the dynamic success of intramedullary fixation of fractures of the femur and tibia, there was speculation that intramedullary nailing might be more appropriate for humeral shaft fractures than plating. The theoretical advantage of intramedullary nailing included less invasive surgery, an undisturbed fracture hematoma and use of a load sharing device support. The phenomenon success of interlocking nailing in long bones like femur and tibia is not seen in humerus. The IMIL nail may also cause rotator cuff injury and impair the movements at shoulder joint. According to recent studies ${ }^{8-10,12}$ the preferred method of fixation of humerus is by dynamic compression plate. This study compared the outcomes of dynamic compression plating and interlocking nailing for the fracture shaft of humerus.

\section{Conclusion}

No single treatment option is superior in all circumstances for a particular fracture and each case has to be individualised. Based on the findings of this study it may be concluded that, nailing and plating are equally effective for the treatment of shaft of humerus fractures in terms of fracture union time, functional outcome and complications.

\section{Summary}

The treatment of humeral shaft fractures using IMN and DCP is controversial especially considering fracture union, complications and outcome. The present study was an attempt to determine the functional outcome for shaft of humerus fractures using IMN and DCP.

This hospital based one year prospective study was done in the Department of Orthopaedics, KLES Dr. Prabhakar Kore Hospital and Medical Research Centre, Belgaum from January 2014 to December 2014. A total of 30 patients with humeral shaft fractures were studied. Based on the method of treatment, patients were divided into two groups of 15 each as group A (Nailing) and group (Plating). Patients were followed up for the fracture union, complications and functional outcome based on Constant Murley score.

Majority of the patients $(80 \%)$ in group A were males while in group B, $53.33 \%$ of the patients were males. The male to female ratio in group A was $4: 1$ as against 1.14:1 in group B $(\mathrm{p}=0.121)$. The commonest age group was 31 to 45 years with $46.67 \%$ of the patients each in group A and group B $(\mathrm{p}=1.000)$. The mean age was comparable in both the groups $(34.33 \pm 11.27$ vs. $33.20 \pm 11.73$ years; $p=0.789)$. Other preoperative characteristics including, side of the fracture, type of the fracture, mode of injury and associated injuries were comparable in group A and group B $(p>0.050)$. In patients with group A, shoulder stiffness and superficial infection were present in $13.33 \%$ and $6.67 \%$ of the patients respectively. In group B, radial nerve palsy and superficial infection were noted in $6.67 \%$ and $13.33 \%$ of the patients respectively. The fracture union time in group was $\leq 8$ weeks in $46.67 \%$ of the patient compared to $40 \%$ in group B and the mean fracture union time $(8.8 \pm 3.72$ vs $9.86 \pm 2.97$ weeks; $\mathrm{p}=0.394$ ) was comparable. Based on Constant Murley score, $73.33 \%$ of the patients had excellent functional outcome in group A compared to $80 \%$ in group $\mathrm{B}(\mathrm{p}=0.523)$ and mean Constant Murley Scores $(80.93 \pm 15.47$ vs $84.60 \pm 14.30$; $\mathrm{p}=0.506)$ were also almost comparable.

Intramedullary nailing and DC plating are equally effective for the treatment of shaft of humerus fractures.

\section{References}

1. Sai CH, Fong YC, Chen YH, Hsu CJ, Chang $\mathrm{CH}$ et al. The epidemiology of traumatic humeral shaft fractures in Taiwan. Int Orthop. 2009; 33:463-7.

2. Ekholm R, Adami J, Tidermark J, Hansson K, Tornkvist $\mathrm{H}$, Ponzer S. Fractures of the shaft of the humerus. An epidemiological study of 401 fractures. J Bone Jt Surg. 2006; 88-B:1469-73.

3. Tytherleigh-Strong G, Walls N, Mcqueen MM. The epidemiology of humeral shaft fractures. J. Bone Jt Surg. 1998; 80-B:249-53.

4. Mueller ME, Nazarian S, Koch P, Schatzker J. The comprehensive classification of fractures of long bones. New York, Springer Verlag, 1990.

5. Gradl G, Jupiter JB. Current Concepts Review - fractures of the shaft of the humerus. Acta Chirurgiae Orthopaedicae ET Traumatologiae Čechosl. 2013; 80:321-7. 